\title{
Fundus changes in histologically confirmed sarcoidosis
}

\author{
D. J. SPALTON AND M. D. SANDERS \\ From the Medical Eye Unit, St Thomas's Hospital, and the Department of Neuro-Ophthalmology, \\ National Hospital, Queen Square, London
}

SUMMARY We reviewed the clinical features, natural history and visual prognosis of 36 patients with histologically confirmed sarcoidosis. Compatible chest $\mathrm{x}$-ray changes were found in $75 \%$ of patients. Periphlebitis was the commonest fundus feature. Disc changes were seen in a substantial number of patients, and the condition can present as unilateral disc oedema. The disease seems primarily to involve equatorial retinal veins, and occlusions of a hemisphere branch vein or central retinal vein did not occur. Changes in the subretinal pigment epithelium were noted in a substantial number of patients but did not produce visual morbidity, and these patients seemed to have less florid periphlebitis than others. The disease has a low visual morbidity unless neovascularisation develops; the treatment of this remains controversial.

Ocular involvement occurs in about a quarter of patients with sarcoidosis during some stage of their illness, most frequently it affects only the anterior segment, but involvement of the posterior segment of the eye is not uncommon. ${ }^{1-4}$ The features of posterior segment involvement are well recognised and include vitreous cellular infiltration, periphlebitis, chorioretinal scarring, optic disc swelling, macular oedema, and rarely neovascularisation. ${ }^{56}$ Estimates of the frequency of fundus disease vary according ot the referral source of the patients, criteria for diagnosis, and methods of examination, but it would seem that about $25 \%$ of patients with ocular sarcoid will show evidence of posterior segment involvement during their illness and indeed this may be the only ocular manifestation. ${ }^{34}$

In this study a group of patients with histologically confirmed sarcoidosis were studied to identify the features of fundus involvement and to relate these features to the natural history and visual prognosis of the disease.

\section{Materials and methods}

From the records of the Eye and Pathology Departments at St Thomas's Hospital and the National Hospital for Nervous Diseases we abstracted those

Correspondence to Mr D. J. Spalton, Medical Eye Unit, St Thomas's Hospital, Lambeth Palace Road, London SE1 7EH. of 36 patients who had confirmation, either by biopsy or Kveim test, of their sarcoidosis. All patients had fundus involvement, such as periphlebitis, optic disc swelling, macular oedema, or pigment epithelial changes, apart from a vitreous cellular infiltration, as this can occur with a severe anterior uveitis in the absence of other signs of posterior segment involvement.

Most patients had been diagnosed and treated during the 1970 s, only a few having presented in the 1960s. The records and fundus photographs of each patient were reviewed, and, when possible, patients were recalled for further examination. All patients had had their pupils dilated, and careful funduscopy and in most cases fundus photography had been performed.

\section{DIAGNOSIS}

Diagnosis of sarcoidosis can be difficult. Ideally one would wish to demonstrate noncaseating granulomas occurring in several different organs, but biopsy of these is frequently impossible and in many cases the diagnosis remains circumstantial. The Kveim test is cumbersome and can be influenced by concurrent steroid therapy; pathological interpretation of the result is not always easy and there is reckoned to be a false positive rate of $2-3 \%$ of Kveim biopsies. ${ }^{1}$ The test is positive in about $70 \%$ of cases of active sarcoidosis, most frequently at the onset of the illness, and has a declining diagnostic capability as the illness becomes chronic. Neverthe- 
Table 1 Incidence of age of presentation

\begin{tabular}{|c|c|c|c|c|c|c|c|c|c|c|c|}
\hline Age & $15-20$ & $20-25$ & $25-30$ & $30-35$ & $35-40$ & $40-45$ & $45-50$ & $50-55$ & $55-60$ & $60-65$ & \\
\hline $\mathbf{F}$ & 1 & 4 & 3 & 3 & 1 & 2 & 2 & 2 & 0 & 1 & 19 \\
\hline $\mathbf{M}$ & 2 & 4 & 2 & 3 & 2 & 1 & 1 & 0 & 2 & 0 & 17 \\
\hline Total & & & & & & & & & & & 36 \\
\hline
\end{tabular}

Fig. 1 Unilateral optic disc swelling with vitreous cellular infiltration presenting in a 30-year-old woman. Liver biopsy showed noncaseating granulomas. The disc returned to normal with systemic steroids.
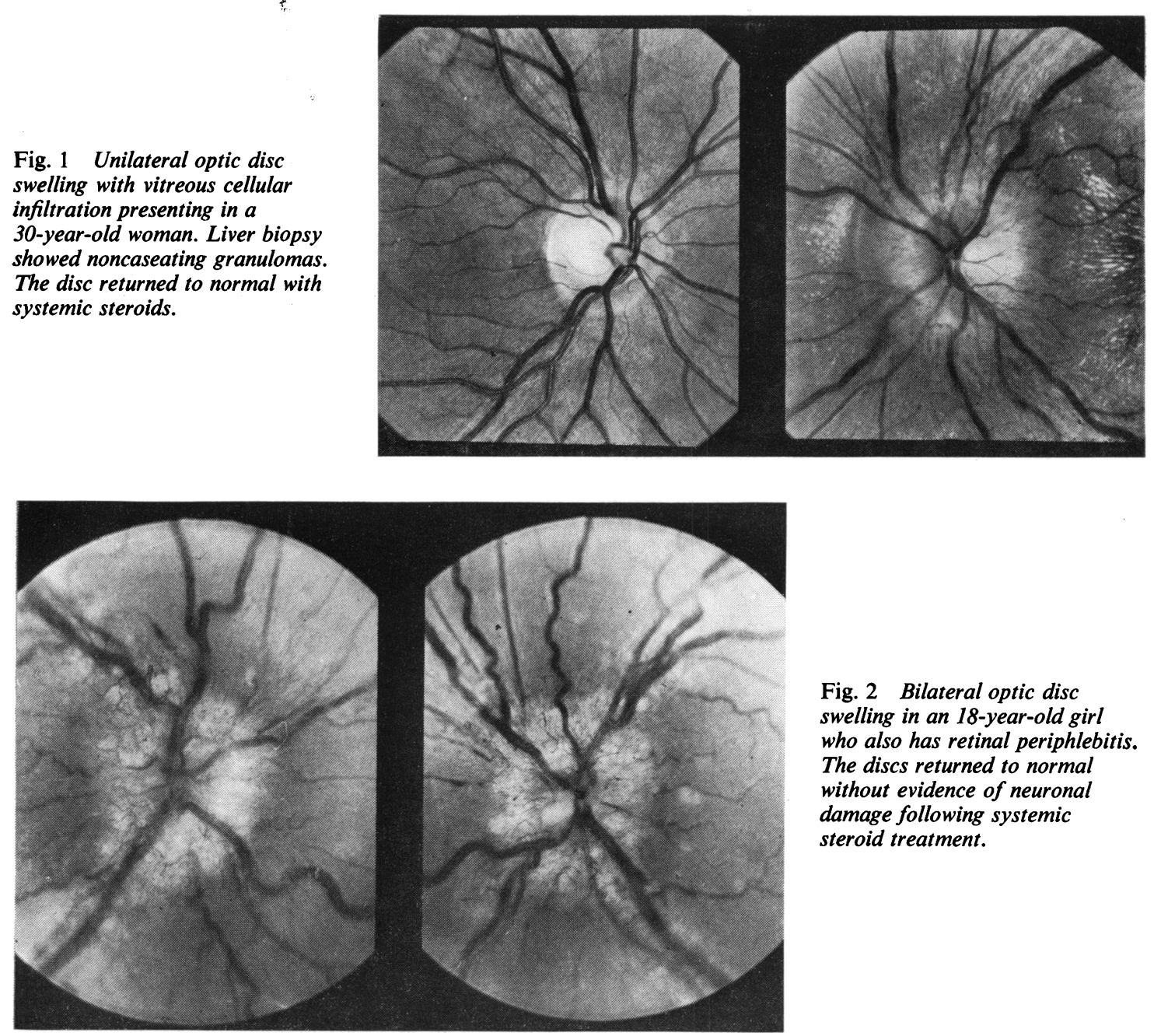

Fig. 2 Bilateral optic disc swelling in an 18-year-old girl who also has retinal periphlebitis. The discs returned to normal without evidence of neuronal damage following systemic steroid treatment. less, the Kveim test remains the mainstay of histological confirmation of the disease.

Of the 36 patients in the series the disease was confirmed by Kveim test in 28 and by biopsy of lymph nodes or other organs in 8. There was a male:female ratio of $17: 19$ and most patients presented as young adults, but a few continued to present until later life (Table 1). Twenty-seven patients $(75 \%)$ had chest $\mathrm{X}$-ray changes compatible with sarcoidosis, 2 patients had doubtful chest $\mathrm{x}$-rays, and in 7 patients there was no radiological evidence of pulmonary sarcoidosis. We made no effort to correlate the eye findings with involvement of other systems, as the patients were not all investigated with uniform thoroughness for this. Nevertheless, all patients except 2 had some other clinical evidence of sarcoidosis apart from their ocular signs, and only 3 had overt central nervous system 


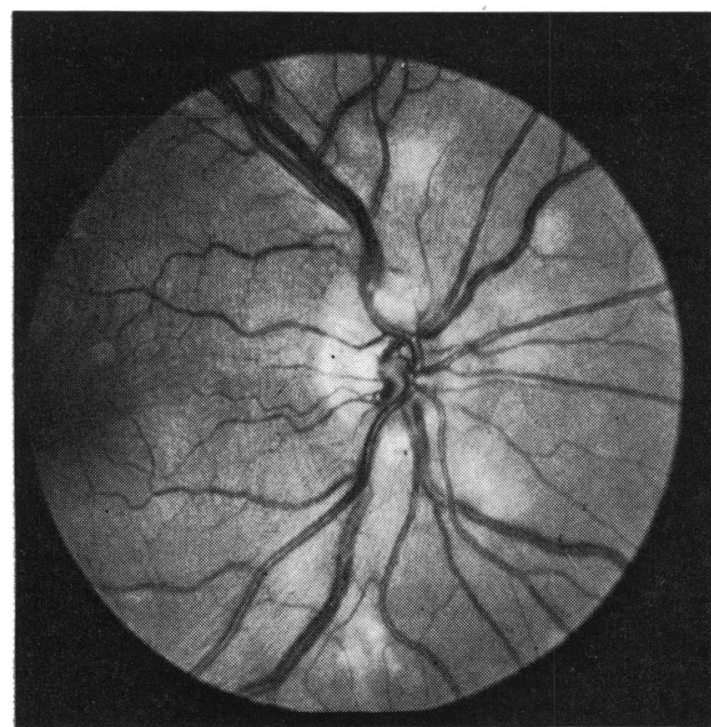

3A

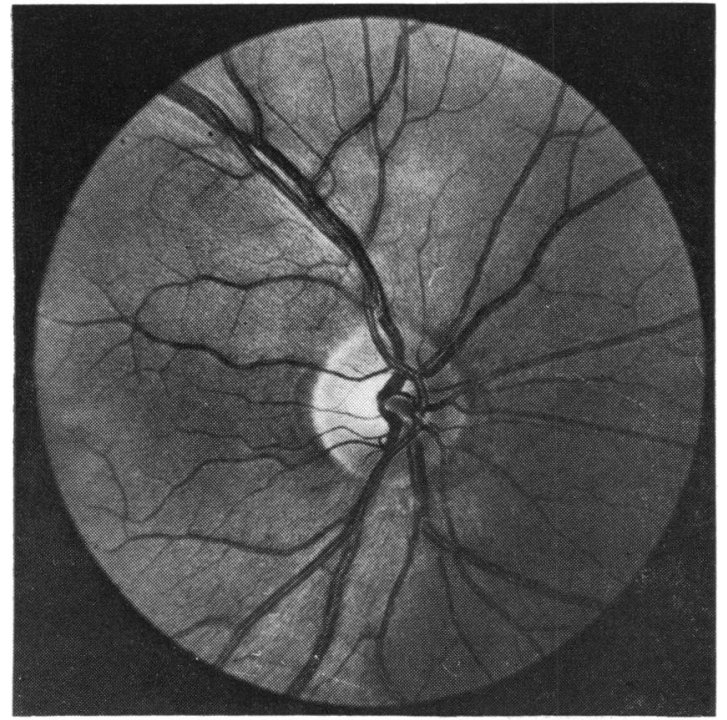

$3 C$

disease ( 1 intracranial, 2 spinal), and these 3 patients had negative chest $x$-ray findings.

Recently, raised serum levels of angiotensin converting enzyme have been used as an aid in the diagnosis of sarcoid, ${ }^{7}$ but we have not found this test helpful in the absence of overt evidence of clinical disease.

\section{Results}

Twenty-eight patients $(78 \%)$ showed signs of an anterior uveitis on presentation, but in 2 of these the

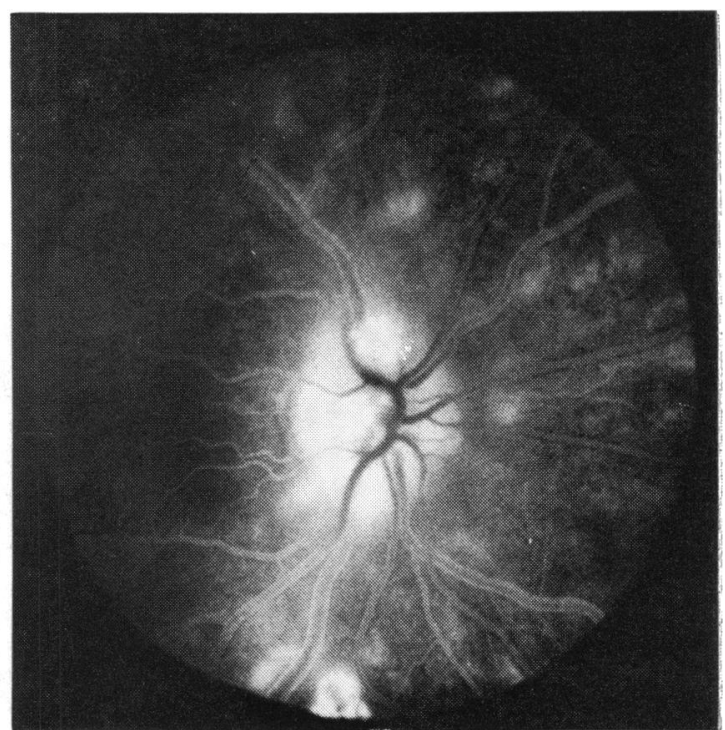

3B

Figs. 3A, B, C Black-and-white fundus photograph $(3 A)$ and fluorescein angiogram (3B) showing the right optic disc of a 16-year-old boy. There is mild optic disc swelling and patchy fluffy subretinal changes with fluorescein leakage. Six months later the disc and subretinal changes have resolved without atrophic pigment epithelial change (3C).

inflammation was mainly uniocular. Eight $(22 \%)$ patients had no signs of anterior segment involvement in either eye on presentation. From the total of 36 patients $6(18 \%)$ had markedly asymmetrical involvement of their eyes and another $4(11 \%)$ appeared to have only uniocular disease, so that almost a third of our patients had grossly asymmetrical ocular involvement. Two patients presented with unilateral optic disc swelling (Fig. 1) and a vitreous cellular infiltrate. In the total series 1 other patient had unilateral disc swelling, and 10 patients. had disc swelling or bilateral leakage of fluorescein 


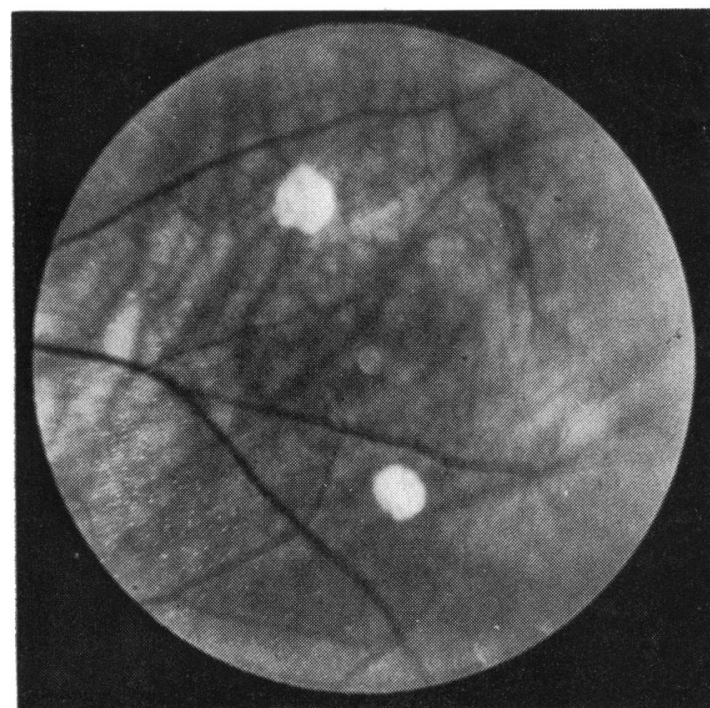

4A

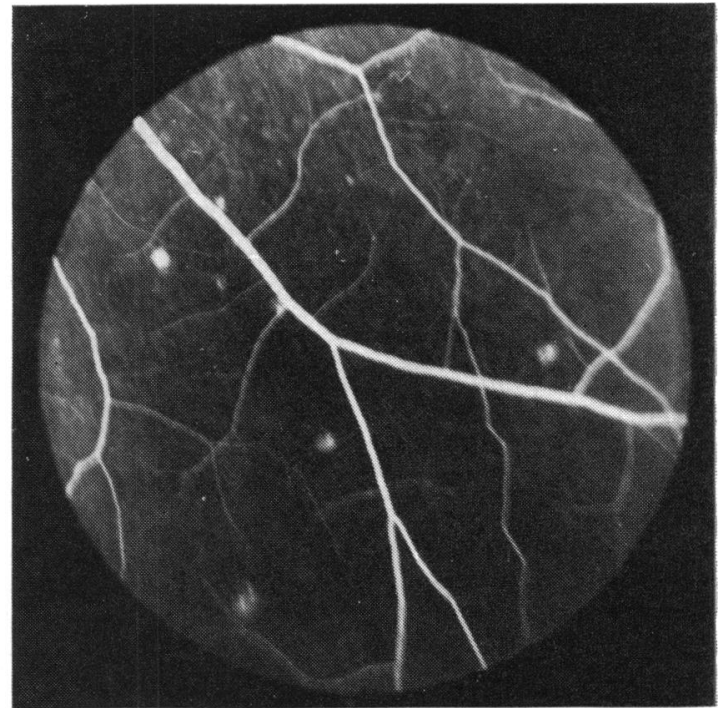

4B

Figs. 4A, B Pigment epithelial atrophy is seen more commonly in the inferior equatorial area of the fundus.

Sometimes these areas are quite large, resembling cobblestone degeneration (4A) or small and indistinct and seen only on careful ophthalmoscopy or fluorescein angiography $(4 B)$.

from the disc, so that optic disc changes of some degree were a feature of the ocular condition in a total of 13 patients $(39 \%)$ (Figs. 1, 2, 3).

By definition all our patients had a vitreous cellular infiltrate. Periphlebitis was seen in 22 patients $(73 \%$ of patients where it was recorded), and mainly bilateral. It was absent in 8 patients, and

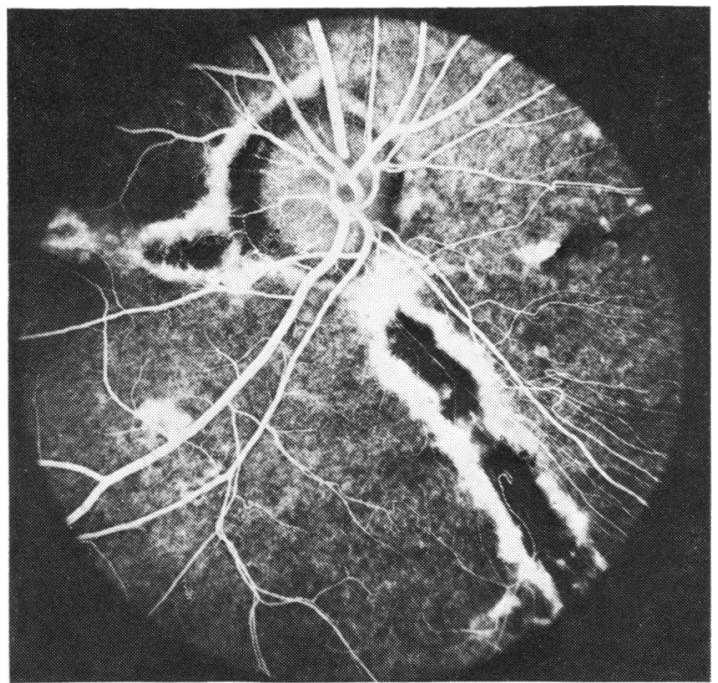

Fig. 5 Fluorescein angiogram showing chorioretinal scarring presumed to result from previous severe retinal periphlebitis (Table 4, patient 6). no record of this was made in the notes of 6 patients.

A characteristic pigment epithelial change was seen in 13 patients $(36 \%)$. This was a focal and discrete subretinal mottling, sometimes involving the posterior pole (Figs. 3A, B, and C), but more commonly affecting the inferior equatorial area of the fundus, rather like extensive cobblestone degeneration. The lesions varied in extent from being large and extensive (Fig. 4A) to quite subtle lesions, only found on careful indirect ophthalmoscopy (Fig. 4B) or re-examining fundus photographs. Of the 13 patients who showed signs of subretinal changes 9 had bilateral disease and 4 unilateral. One other patient had chorioretinal scarring along an area of periphlebitis (Fig. 5), and other 4 patients were impossible to assess, having had laser photocoagulation, vitreous haemorrhage, or retinal detachment. These findings are summarised in Table 2.

Table 2 Ocular changes in sarcoidosis

\begin{tabular}{lllll}
\hline & Both eyes & Uniocular & Absent & No record \\
\hline $\begin{array}{l}\text { Anterior uveitis at } \\
\text { presentation }\end{array}$ & $26(72 \%)$ & $2(6 \%)$ & $8(22 \%)$ & - \\
Periphlebitis & $15(42 \%)$ & $7(19 \%)$ & $8(22 \%)$ & $6(17 \%)$ \\
$\begin{array}{l}\text { Disc changes } \\
\text { Mottled pigment }\end{array}$ & $10(27 \%)$ & $3(8 \%)$ & $23(64 \%)-$ \\
epithelial changes & $9(25 \%)$ & $4(11 \%)$ & $23(64 \%)-$ \\
New vessels & $4(11 \%)$ & $4(11 \%)$ & $28(78 \%)-$ \\
\hline
\end{tabular}




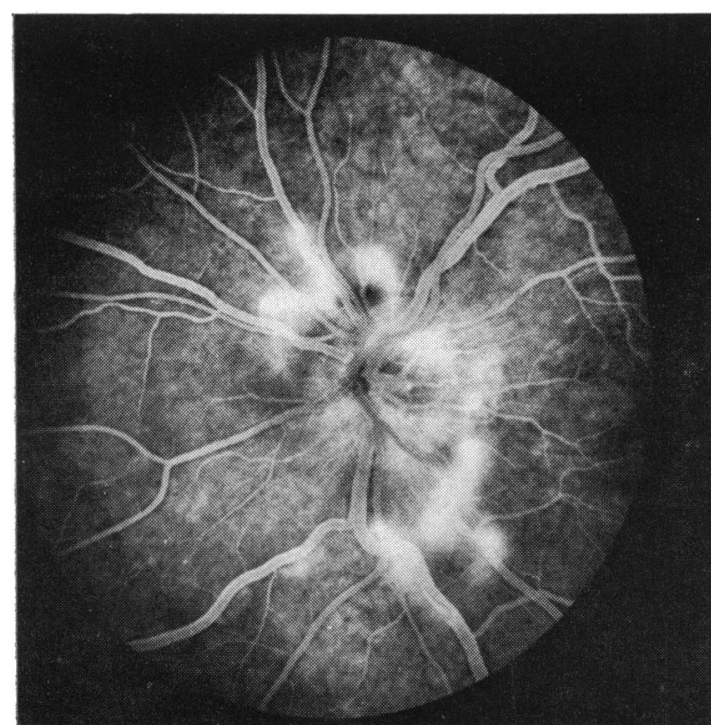

6A

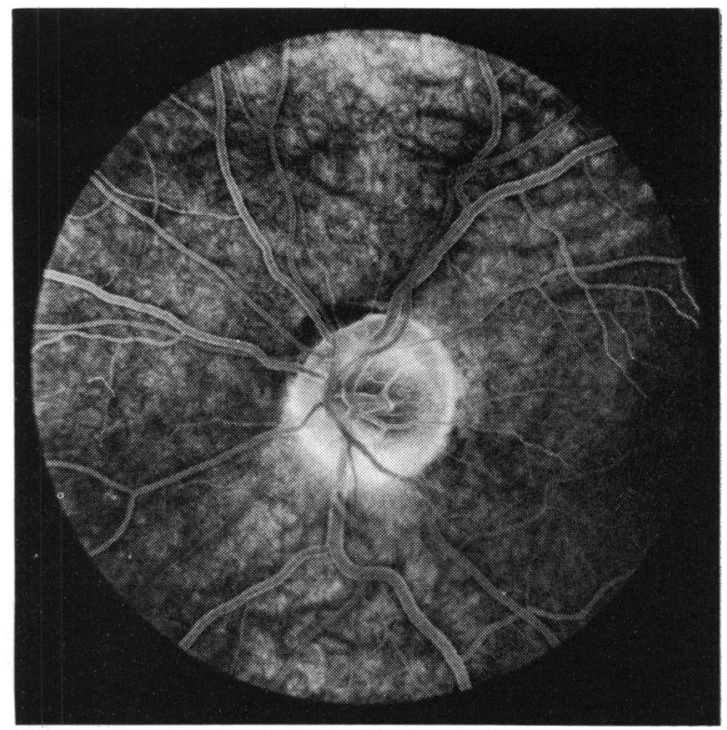

6B

Figs. 6A, B Fluorescein angiogram showing thready new vessels on the optic disc of a 27-year-old woman. There was no peripheral vascular closure (6A). Five months later, after systemic steroids, fluorescein angiography (6B) shows the neovascularisation has regressed completely without visual deficit (Table 3, patient 2).

Table 3 New vessels

\begin{tabular}{|c|c|c|c|c|c|}
\hline & \multicolumn{2}{|l|}{$\boldsymbol{R}$} & \multicolumn{2}{|l|}{$L$} & \multirow{2}{*}{$\begin{array}{l}\text { Comment } \\
\text { (and references to Table 4) }\end{array}$} \\
\hline & Disc & Periphery & Disc & Periphery & \\
\hline 1 & + & - & - & - & $\begin{array}{l}R \text { vitreous haemorrhage at } \\
\text { presentation. }(4,1)\end{array}$ \\
\hline 2 & + & - & + & - & No closure \\
\hline 3 & + & - & - & - & Seen in later stages $(4,2)$ \\
\hline 4 & + & + & + & + & Successful laser $(4,8)$ \\
\hline 5 & + & - & + & - & No closure \\
\hline 6 & + & - & + & - & $\begin{array}{l}R \text { vitreous haemorrhage at } \\
\text { presentation. }(4,5)\end{array}$ \\
\hline 7 & - & + & - & - & Laser but VA reduced $(4,3)$ \\
\hline 8 & - & - & - & + & Field loss $(4,7)$ \\
\hline
\end{tabular}

VA $=$ visual acuity.

Eight patients $(22 \%)$ showed evidence of neovascularisation and are summarised in Table 3. This involved the optic disc in 6 patients, 2 of these patients having no signs of peripheral vascular closure (Figs. 6A and B, 7A and B). Two other patients developed peripheral neovascular changes at the sites of branch retinal vein occlusions (Figs. 8A, B, C, D, and 9A and B).

Neovascularisation was the most significant factor contributing to a poor prognosis (Table 4). The eventual visual acuity was less than 6/9 in one eye of 3 patients (all secondary to retinal neovascularisation) and less than this level in 2 other patients, one due to macular oedema in each eye. The other was severely incapacitated from neovascularisation in each eye; he had presented many years ago and had been treated with intravitreal streptokinase, which probably contributed to the eventual visual loss. Two other patients had lost visual field in one eye from peripheral neovascularisation, and 1 other had signs of optic atrophy together with intracranial sarcoid; he was too ill to co-operate with perimetry. Consequently only 2

\section{Table 4 Causes of visual morbidity}

\begin{tabular}{|c|c|c|c|}
\hline \multirow{2}{*}{ Patient } & \multicolumn{2}{|c|}{ Visual acuity } & \multirow{2}{*}{$\begin{array}{l}\text { Cause } \\
\mathbf{R} \text { disc-retinitis proliferans. } \\
\text { Vitreous haemorrhage at presentation }\end{array}$} \\
\hline & HM & $6 / 5$ & \\
\hline 2 & HM & $6 / 5$ & $\begin{array}{l}\text { R macular scarring, probably from } \\
\text { disc new vessels }\end{array}$ \\
\hline 3 & $6 / 36$ & $6 / 5$ & $\begin{array}{l}\mathbf{R} \text { persistent macular oedema following } \\
\text { laser to peripheral new vessels }\end{array}$ \\
\hline 4 & $6 / 60$ & $6 / 18$ & $\begin{array}{l}\text { Macular oedema, no new vessels, } \\
\text { both eyes }\end{array}$ \\
\hline 5 & NPL & CF & $\begin{array}{l}\text { Disc new vessels both eyes. } \mathbf{R} \text { vitreous } \\
\text { haemorrhage at presentation }\end{array}$ \\
\hline 6 & $6 / 9$ & $6 / 6$ & $\mathbf{R}$ uniocular optic atrophy \\
\hline 7 & $6 / 6$ & $6 / 9$ & $\begin{array}{l}\text { L peripheral new vessels and field } \\
\text { loss-no laser therapy }\end{array}$ \\
\hline 8 & $6 / 5$ & $6 / 5$ & $\begin{array}{l}\text { Disc and peripheral new vessels both } \\
\text { eyes, treated with laser both eyes }\end{array}$ \\
\hline
\end{tabular}

CF $=$ counting fingers. $\mathbf{H M}=$ hand movements.

NPL $=$ no perception of light. 


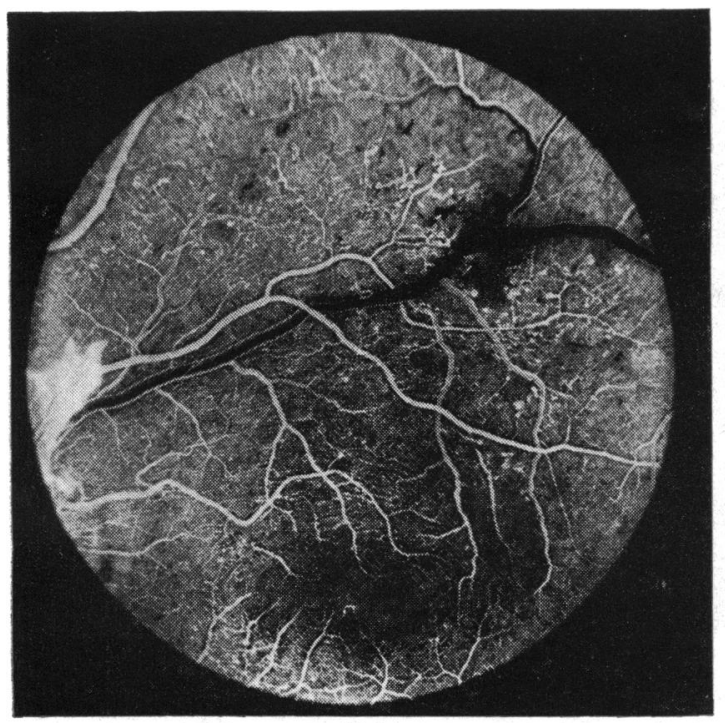

$7 \mathrm{~A}$

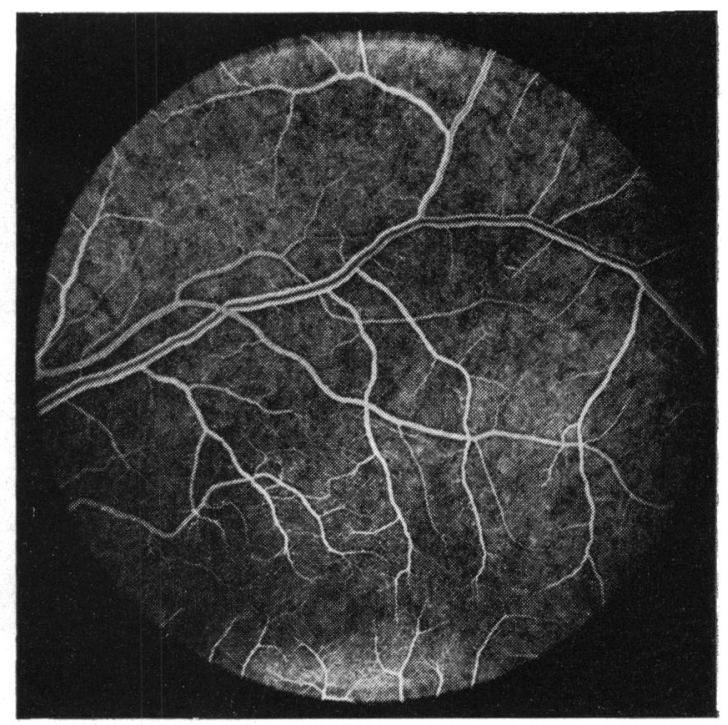

7B

Figs. 7A, B Fluorescein angiogram (7A) showing optic disc neovascularisation, capillary dilatation, and small areas of capillary closure in the posterior pole in a 21 -year-old woman. There was no peripheral vascular closure. Four months later, after systemic steroids, fluorescein angiography (7B) shows that optic disc neovascularisation has regressed and there has been vascular remodelling in the posterior pole (Table 3, patient 5).

patients suffered severe visual loss in both eyes, 3 patients had severe visual loss in one eye, and another 3 patients lost visual field to some extent.

\section{Discussion}

By selecting patients for our series with histological evidence of sarcoidosis we preselected a group who have probably been more fully investigated than other patients and therefore may have more severe or unusual disease. Both the Medical Eye Unit at St Thomas's Hospital and the National Hospital for Nervous Diseases act as referral centres and therefore may also attract atypical patients outside the normal spectrum of the disease. However, the age and sex incidence of the patients in our study corresponds in broad terms with generally recognised patterns, ${ }^{13} 8$ and therefore our results may have some relevance to the disease in general. We made no effort to correlate ocular involvement with that of other systems. This has been done by many other authors, and not all our patients were investigated with the same thoroughness or to the same extent for extraocular involvement. Our figures show that a routine chest $\mathrm{x}$-ray is the most helpful diagnostic test, being positive in $75 \%$ of patients, and this again corresponds to the experience of others.

Inflammatory signs of varying severity were seen in the anterior segment of $78 \%$ of patients on presentation, and this is similar to figures reported $(8: 75 \%$, $6: 84 \%$ ), but it is interesting to note that a substantial number $(22 \%)$ had disease limited to the posterior segment of the eye which might have been missed on more superficial examination, and unilateral disease or grossly asymmetrical disease was not uncommon, being seen in almost a third of all patients. By definition all our patients had evidence of posterior uveitis, with vitreous cellular infiltrate and frequently accumulations or 'snowballs' on the posterior vitreous face, vitreous gel, or on the retinal surface in the inferior fundus. All our patients had other signs of fundus involvement, such as periphlebitis, optic disc swelling, or chorioretinal scarring as vitreous cellular exudation can occur with an isolated severe anterior uveitis.

\section{PERIPHLEBITIS}

Perivasculitis was first described in sarcoidosis by Walsh, ${ }^{9}$ but these lesions are by no means specific to sarcoidosis and occur in other types of retinal vasculitis. Perivasculitis in our patients was limited to involvement of retinal veins, and no patient showed evidence of any retinal artery inflammation. The small branch veins in the equatorial fundus were most commonly involved in degrees of varying severity from gross perivascular creamy white exudation to subtle changes demonstrated only by 
Figs. 8A, B, C, D Black-andwhite fundus photograph showing gross periphlebitis of an equatorial retinal vein in a 37-year-old man. This resulted in vascular occlusion and neovascularisation ( $8 B$ plus fluorescein angiogram $8 C$ ). Although the new vessels were destroyed by laser coagulation, to chronic macular oedema. (8D) Table 4, patient 3). visual acuity remained at $6 / 36$ due

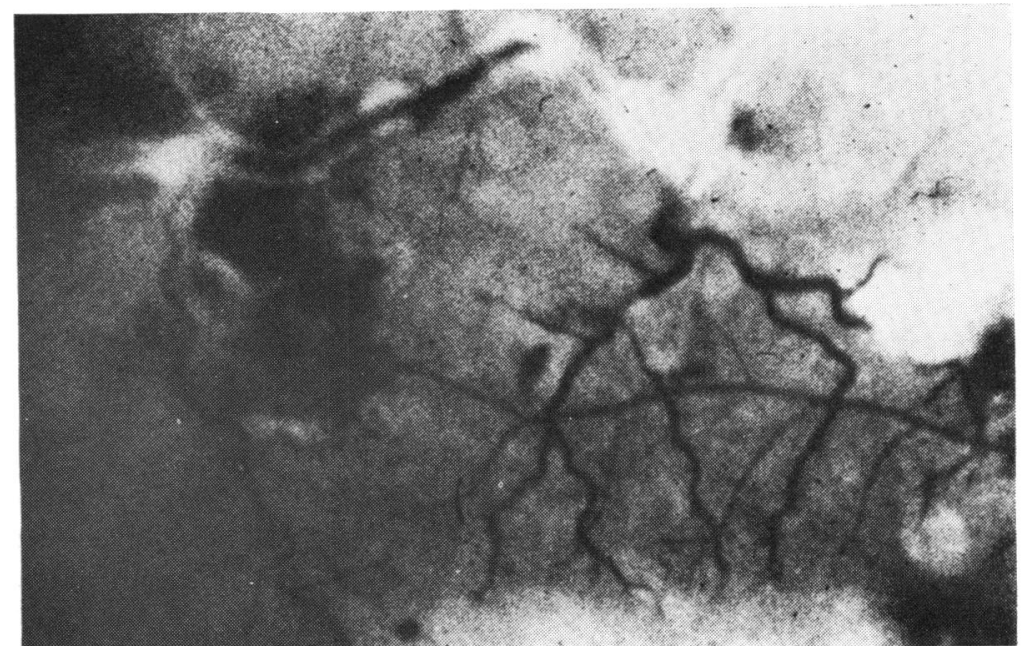

8A

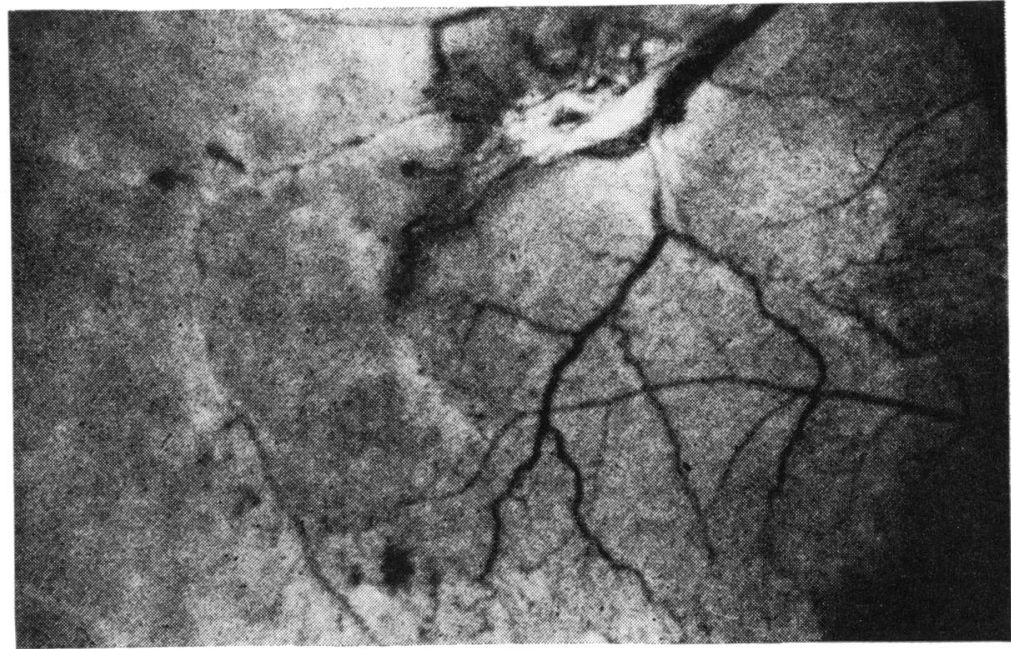

8B
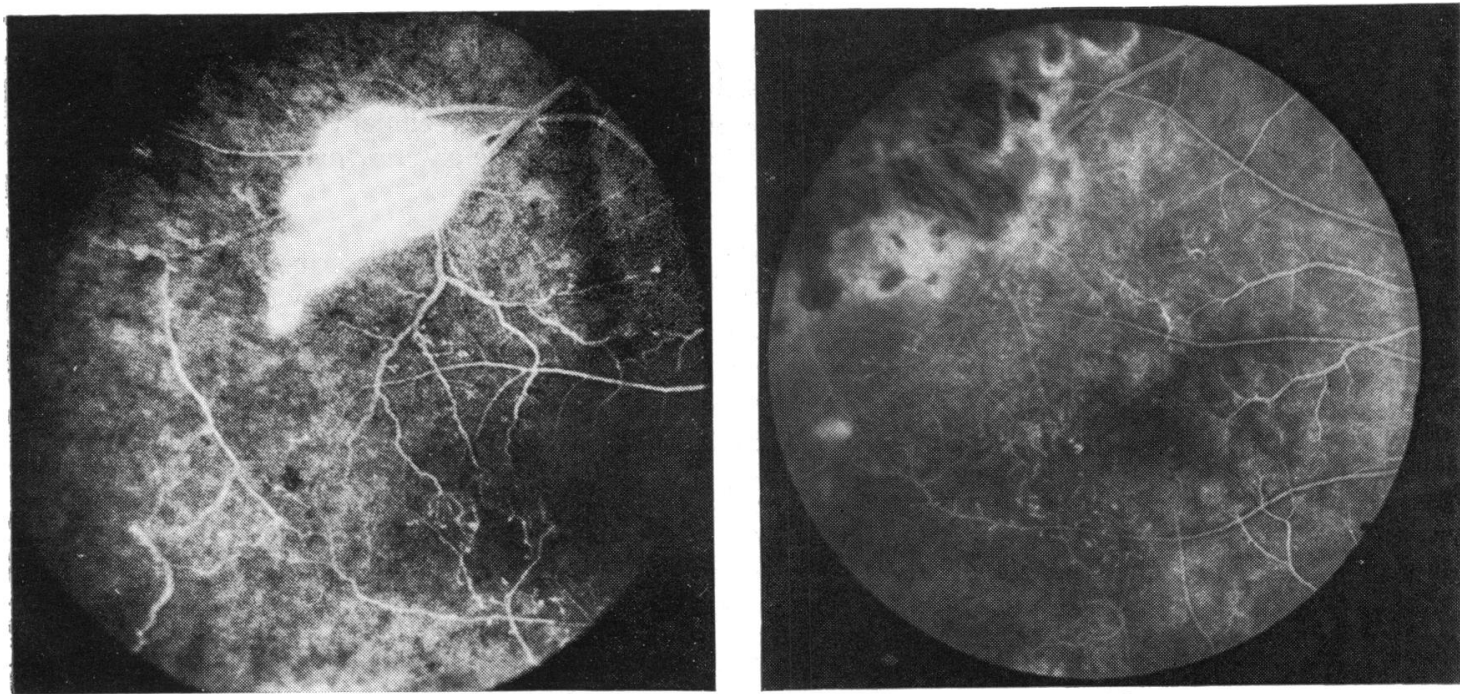


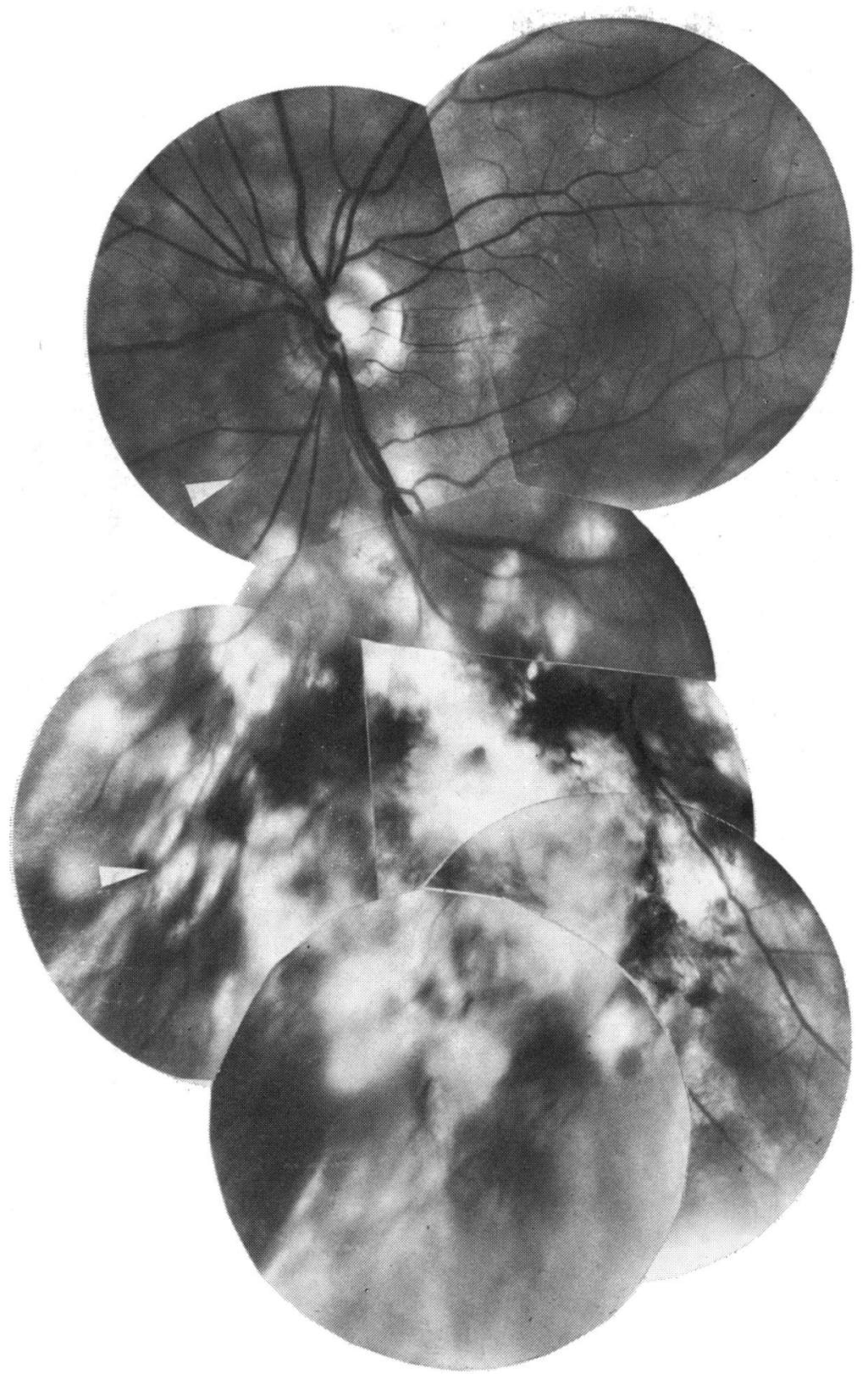

Fig. 9A Composite black-andwhite fundus photograph showing patchy pigment epithelial atrophy increasing in density towards the periphery (arrows) with a dense vitreoretinal scar at the site of previous neovascularisation.

fluorescein angiography. Areas of involvement were frequently segmental, and severe inflammation at these sites sometimes led to vein occlusion and peripheral capillary closure (Figs. 8 and 9). However, and in distinction to our experience in Behçet's disease, ${ }^{10}$ major hemisphere vein occlusions did not occur nor were central retinal vein occlusions seen in any of our patients. The perivenous lesions tended to resolve dramatically on steroid therapy, but occasionally the inflammation was severe, disturbing the underlying pigment epithelium, and focal atrophic changes occurred along the affected vessels (Fig, 5).

OPTIC DISC CHANGES

Swelling of the optic disc in sarcoidosis can result from either a severe posterior uveitis, presumably inducing local vascular leakage in the nerve head, ${ }^{11}$ 
Fig. 9B Composite fluorescein angiogram demonstrates the quiescent retinal scar with peripheral vascular closure. This patient was unusual in that he had evidence of pigment epithelial change and peripheral neovascularisation. (Table 4. patient 7).

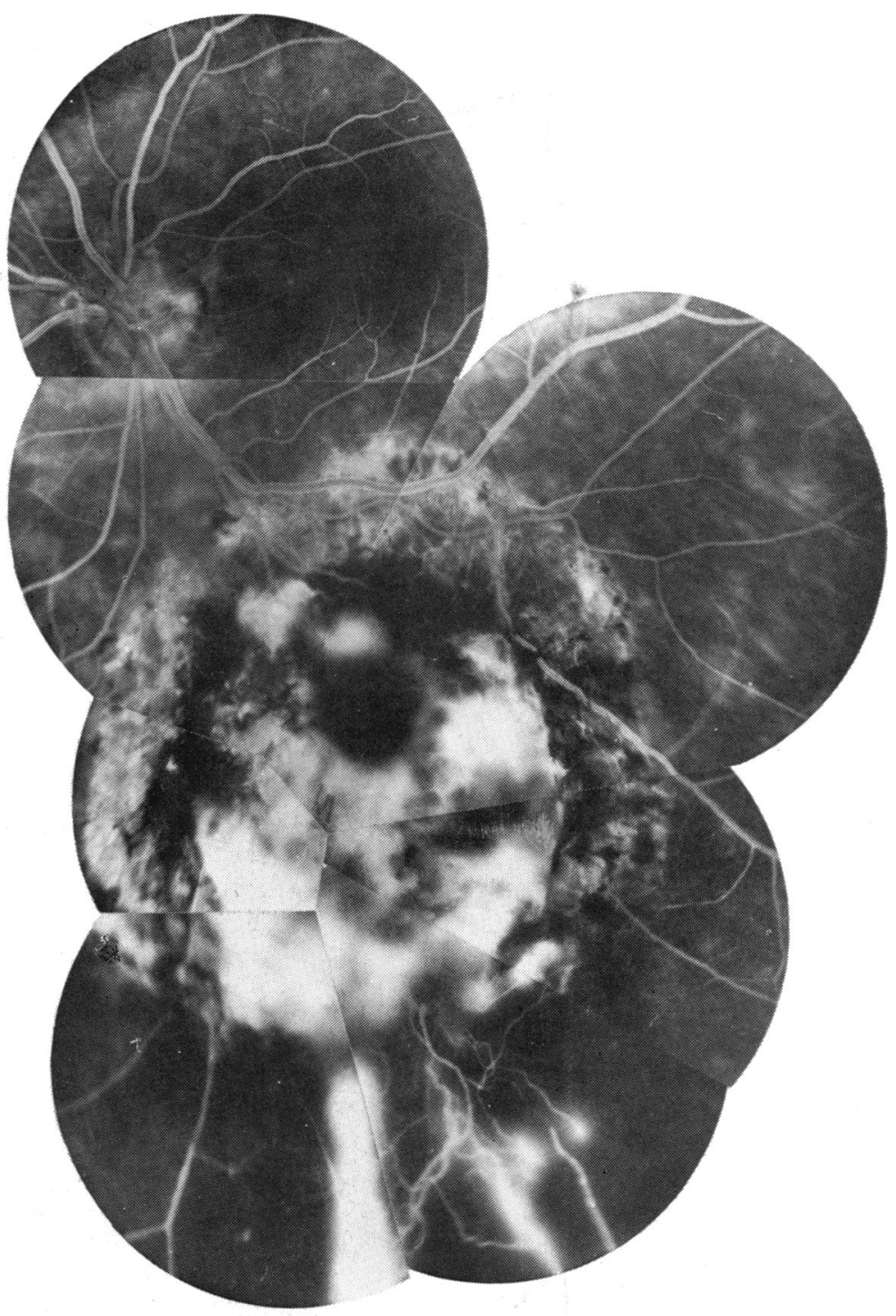

or direct invasion of the optic disc, distal nerve, or nerve sheath by granulomatous tissue. ${ }^{12}$ Optic disc changes of variable and usually mild degree were a feature of the disease in 13 patients $(39 \%)$ and most easily shown by fluorescein angiography. It is impossible to distinguish on clinical grounds what the underlying aetiology was, but the course of the disc swelling seemed to parallel the uveitis and to resolve with it, and this would suggest that frequently local vascular leakage might be the underlying aetiology. Optic disc involvement in sarcoidosis has been thought to be associated with a high incidence of disease of the central nervous system, 5413 but in our series only 1 patient had overt intracranial disease with optic atrophy and another 2 had transient spinal signs.

Of particular interest in our series were 2 patients who were referred with marked unilateral disc swelling (Fig. 1); detection of posterior uveitis spared the patients from undergoing unnecessarily invasive intracranial investigations. Our patients with optic disc involvement responded well to steroid therapy, and the swelling resolved without obvious neuronal damage in all cases. This has been observed previously. ${ }^{14}$

PIGMENT EPITHELIAL CHANGES

Focal subretinal lesions were seen in a substantial 


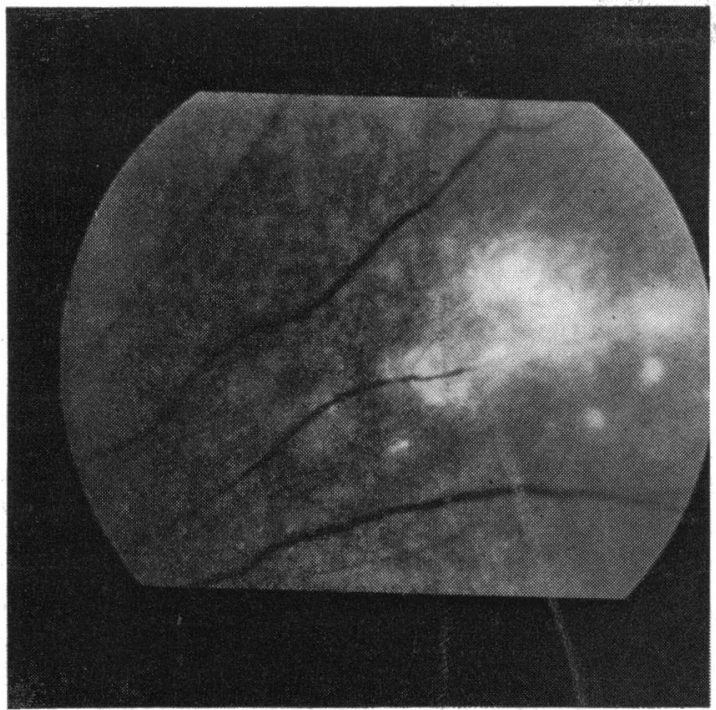

10A

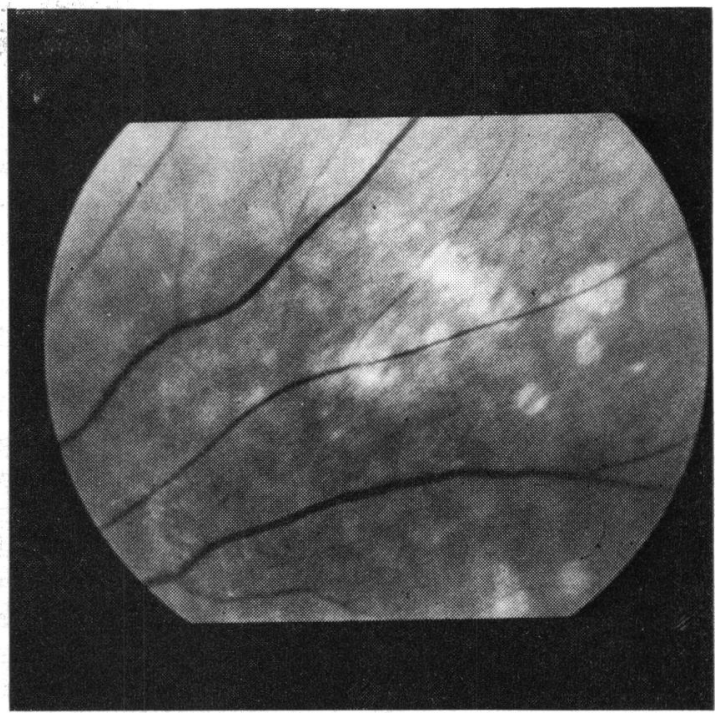

10B

Figs. 10A, B Black-and-white fundus photograph showing the evolution of the creamy fluffy subretinal lesions (10A) to quiescent area of patchy pigment epithelial atrophy (10B) some months later.

number of patients $(36 \%)$. This sometimes involved the posterior pole (Figs. 3A and B), but more commonly were seen in the equatorial retina, particularly inferiorly (Figs. 4A and B) and are similar to the 'en taches du bougie' observed by Franschetti and Babel. ${ }^{15}$ In no patient did they appear to contribute to the visual morbidity. The exact site of this lesion is open to doubt. Some authors ${ }^{1516}$ have speculated that they are a sign of granuloma formation in the choroid, and indeed the size of the lesions frequently corresponds to the approximate size of a choroidal vascular lobule, but pathology reported by Gass and Olson ${ }^{12}$ suggested that a primary pigment epithelial location is more likely. We have seen the peripheral lesions evolve from a creamy soft yellowish focus to an area of pigment epithelial atrophy over a period of months (Figs 10A and B), but lesions at the posterior pole, although extensive, did not appear to cause such full thickness scarring (Figs. 3 and 9). We also noted a tendency for the patients with extensive subretinal changes to have less marked periphlebitis and consequently neovascularisation, and vice versa. This might be related to a tendency for different blood vessels to be involved in the granulomatous process. Some of these patients would appear to have a similar fundus condition to that recently described as 'bird shot retinopathy.'17 This may indicate that sarcoidosis is aetiologically involved at least in some of these patients and therefore that bird shot retinopathy might not be a specific or homogeneous condition, but merely describe a fundus appearance induced by a number of agents.

\section{NEOVASCULARISATION}

Neovascularisation was found in 8 patients $(22 \%)$. It occurred on the optic disc in 5 patients ( 8 eyes), optic discs and peripheries in 1 patient (both eyes), and only in the periphery in 2 patients (one eye each). Two of the patients where the neovascularisation was confined to the discs had no evidence of peripheral closure, but this unusual finding is recognised..$^{18}$ These 2 patients had fine thready new vessels on the discs in both eyes which disappeared with adequate steroid therapy (Figs 6 and 7) and produced no sequelae.

More commonly neovascularisation was assoiated with areas of peripheral closure, and it is likely that this happens as a result of occlusion of small peripheral veins by segments of particularly severe perivenous inflammation (Fig. 8), producing neovascularisation in the well recognised manner. We found no evidence of major hemisphere or central retinal vein occlusions in our patients, and there is no support in our series for the concept of 'central retinal vein vasculitis'19 being caused by sarcoidosis, if indeed this condition does exist. The findings in sarcoidosis contrast with our experience in Behçet's disease, which suggest that major retinal vein occlusion is much commoner in this condition. ${ }^{10}$

The treatment of neovascularisation associated with retinal vasculitis has not been completely 
defined. Two patients (Table 3, nos. 3 and 7) received laser coagulation. One did well, and, while the new retinal vessels were destroyed in the other, vision was lost from macular changes. It is our clinical impression that ocular inflammation should be well controlled before any photocoagulation is attempted.

\section{TREATMENT}

All our patients received steroid treatment, though 7 with relatively mild fundus involvement received only topical treatment. After 3 years of follow-up 16 patients $(44 \%)$ had become inactive, $10(28 \%)$ had active episodes of inflammation requiring treatment, and another $10(28 \%)$ were followed up for less than 3 years or had inadequate follow-up data. While these data suggest that most patients had a relatively short illness (comparable to those with pulmonary hilar gland involvement), it must be remembered that the disease can flare up again after relatively long periods of quiescence, 1 of our patients presenting again after 3 years off treatment. The longest periods of treatment were of 8 and 12 years in 2 patients, but in most of the patients requiring long-term steroid treatment, especially for disease in other organs, it is difficult to decide when the disease is quiescent, and there is always a natural tendency to prolong treatment of patients with chronic and severe disease.

\section{O R B I D I T Y}

Although the number of patients in our series is small, the visual prognosis for sarcoidosis appears to be good, provided neovascularisation does not develop. A final visual acuity of less than $6 / 9$ was eventually recorded in 7 eyes, and 2 patients eventually had severe visual loss in both eyes. One patient (Table 4, no. 4) had acuities of 6/60 and 6/18 due to macular oedema and another (Table 4, no. 5) had no perception of light and counting fingers acuities following disc neovascularisation in both eyes. Anôther 3 patients (Table 4, nos. 1, 2, and 3) had acuities of 6/9 or less in one eye, and in each of these neovascularisation was the major contributing factor. Three other patients (Table 4, nos. 6, 7, and 8) lost visual field, one had optic atrophy, and 2 were due to the effects of neovascularisation (one treated by laser, the other not). We would suggest that neovascularisation in sarcoidosis is a serious complication, and that the natural history may differ from other types of neovascularisation and that the successful visual outcome also depends on adequately controlling the intraocular inflammation.

\section{References}

1 James DG, Neville E, Langley DA. Ocular sarcoidosis. Trans Ophthalmol Soc UK 1976; 96: 133-9.

2 James DG, Neville E, Siltzbach LE, et al. In: Siltzbach LE, ed.. Proceedings of the VII International Conference on Sarcoidosis. Ann NY Acada Sci 1976; 278: 312-34.

3 Obenauf CD, Shaw HE, Sydnar CH, Klintworth GK. Sarcoidosis and its ophthalmic manifestations. Am $J$ Ophthalmol 1978; 86: 648-55.

4 Chumbley LC, Kearns TP. Retinopathy of sarcoidosis. Am J Ophthalmol 1972; 73: 123-31.

5 Gould H, Kaufman HE. Sarcoid of the fundus. Arch Ophthalmol 1961; 65 : 453-6.

6 Sanders MD, Shilling JS. Retinal, choroidal and optic disc involvement in sarcoidosis. Trans Ophthalmol Soc UK 1976; 96: 140-4.

7 Weinreb RN, Kimura SJ. Uveitis associated with sarcoidosis and angiotensin converting enzyme. Am J Ophthalmol 1980; 89: 180-5.

8 Karma A. Ophthalmic changes in sarcoidosis. Acta Ophthalmol (Kbh) 1979; Suppl 141.

9 Walsh FC. Ocular importance of sarcoid. Arch Ophthalmol 1939 ; 21 : 421-38.

10 Sanders MD. (1979) Ophthalmic features in Behçet's disease. In: Lehner T, Barnes CG, eds, Behçet's Syndrome: Clinical and Immunological Features. London: Academic Press, 1979.

11 O'Day J, Shilling JS, Ffytche TJ. Retinal vasculitis. Trans Ophthalmol Soc UK 1979; 99: 163-6.

12 Gass JDM, Olson CL. Sarcoidosis with optic nerve and retinal involvement. Arch Ophthalmol 1976; 94: 945-50.

13 James DG, Zatouroff MA, Trowell J, Rose FC. (1967) Papilloedema in sarcoidosis. Br J Ophthalmol 1967; 51 : 526-9.

14 Hart WM, Burde RM. Optic disc edema in sarcoidosis. Am J Ophthalmol 1979; 88: 769-70.

15 Franschetti A, Babel J. La Chorioretinite en 'taches de bougie' manifestation de les maladie de Besnier-Boeck. Ophthalmologica 1949; 118: 701-10.

16 Laval J. Ocular sarcoidosis. Am J Ophthalmol 1952; 35: $551-4$.

17 Ryan SJ, Maumenee AE. Birdshot retinochoroidopathy. Am J Ophthalmol 1980; 89 : 31-45.

18 Henkind P. Ocular neovascularisation. Am J Ophthalmol 1978; 85: 287-301.

19 Lyle TK, Wybar K. Retinal vasculitis. Br J Ophthalmol $1961 ; 45$ : 778-88. 